\title{
Geociências
}

\section{Avaliação de aspectos texturais e estruturais de corpos vulcânicos e subvulcânicos e sua relação com o ambiente de cristalização, com base em exemplos do Brasil, Argentina e Chile}

\author{
Akihisa Motoki \\ Departamento de Mineralogia e Petrologia Ígnea, Universidade do Estado do Rio de Janeiro \\ E-mail:amotoki@yahoo.com \\ Susanna Sichel \\ Departamento de Geologia, Laboratório de Geologia do Mar, Universidade Federal Fluminense \\ E-mail:susanna@igeo.lagemar.uff
}

\section{Resumo}

Muitos vulcões e corpos subvulcânicos observados no Brasil, Argentina e Chile representam exemplos didáticos que permitem entender a relação entre os aspectos texturais e estruturais de suas rochas constituintes e o ambiente de cristalização dos corpos ígneos. Os corpos vulcânicos, como lavas e fluxos piroclásticos, têm extensão horizontal grande, espessura pequena e planos de contato suborizontais. Por outro lado, muitos corpos subvulcânicos, como os que preenchem condutos e chaminés vulcânicos, possuem extensão horizontal pequena, dimensão vertical grande e planos de contato subverticais. Corpos vulcânicos são constituídos por rochas de granulometria fina, entretanto certos corpos subvulcânicos também são compostos de rochas similares. A granulometria das rochas ígneas é relacionada, principalmente, à taxa de resfriamento magmático e não diretamente à profundidade de posicionamento. Desta forma, a interpretação de modo de ocorrência geológica, a partir das descrições litológicas e petrográfica, é, freqüentemente, impossível, especialmente no caso de rochas piroclásticas. O modo de ocorrência de um corpo ígneo deve ser determinado por meio de observações de campo, sobretudo de afloramentos de contato.

Palavras-chave: vulcão, corpo subvulcânico, textura, estrutura, Argentina, Brasil, Chile.

\begin{abstract}
Many volcanoes and subvolcanic rock bodies observed in Brazil, Argentina, and Chile represent didactic examples that explain the relation between textural and structural aspects of their constituent rocks and crystallization environment of the rock bodies. The volcanic bodies, such as lavas and pyroclastic flows, have large horizontal extension, small thickness, and sub-horizontal contacts plains. On the other hand, many subvolcanic bodies, such as vent-filling rock bodies have small horizontal extension, large vertical dimension, and sub-vertical contacts plains. The volcanic rock bodies are constituted by fine-grained rocks, however some subvolcanic bodies also are made up of similar rocks. The grain-size of igneous rocks is related mainly to magma-cooling rate, and not directly to their emplacement depth. Therefore, the interpretation of geological occurrence mode from the lithological and petrological description is often impossible, especially in case of pyroclastic rocks. Geological occurrence mode of an igneous body must be determined by means of field observations, especially of contact outcrops.
\end{abstract}

Keyword: volcano, subvolcanic body, texture, structure, Argentina, Brazil, Chile. 
Avaliação de aspectos texturais e estruturais de corpos vulcânicos e subvulcânicos e sua relação...

\section{Introdução}

Os dicionários geológicos e livros didáticos da vulcanologia definem os termos "vulcão" e "edifício vulcânico" como sendo uma elevação morfológica formada por meio de erupções vulcânicas e conseqüentes acúmulos de materiais eruptivos na superfície da Terra. As morfologias de relevo negativo, formadas por erupções, tal como cratera de explosão, também podem ser classificadas como vulcões (e.g. MacDonald, 1972; Hatayama et al., 1980; Bates \& Jacson, 1987), isto é, o conceito de "vulcão” abrange vários tipos de morfologias originadas diretamente de erupção, inclusive aqueles que não possuem forma cônica, tais como torres (lava spine), domos (lava dome), escudos (shield), platôs (plateau, mesa) e crateras explosivas (explosion crater, maar).

A erosão remove os materiais constituintes de locais altos e, portanto, com a passagem do tempo, um edifício vulcânico perde sua forma original. Por outro lado, a denudação remove, não somente o edifício vulcânico, como também a superfície regional, chegando a expor as estruturas subvulcânicas, tais como conduto vulcânico, chaminé vulcânica, fissura vulcânica e câmara magmática. Conforme a definição anteriormente citada, a saliência morfológica constituída por corpos subvulcânicos originada de erosão diferencial não corresponde a um vulcão.

A textura de rochas ígneas, sobretudo a granulometria, tem sido considerada como um dos importantes critérios para sua classificação. Zirkel (1837) apresentou a classificação em três categorias, com base na textura, idade e modo de ocorrência geológica: 1 ) equigranulares fanerocristalinas predominantemente plutônicas (gleichmässig körnig porphyrisch vorwiegend plutonische Gesteine); 2) holocristalinas e vítreas pré-terciárias, ou seja, paleovulcânicas (porphyrish und glasig vor tertiär, paläovulkanisch); 3) vulcânicas terciárias e pós-terciárias, neovulcânicas (vulkanisch tertiär und post-tertiär, neo-vulkanisch). Rosenbusch (1877) colocou a granulometria como o critério principal: 1) granulares (körnig); 2) porfiríticas (porphyrisch); 3) vítreas (glasig). Johannsen (1911) e Streckeisen (1973; 1978) sucederam essa idéia, simplificando-a em duas categorias: 1) grossa (phanerides, $\phi \alpha v \varepsilon \rho o \sigma$, coarse-grained); 2) fina (aphanides, $\alpha \phi \alpha v i \delta$, finegrained). Hoje em dia, rochas ígneas são classificadas, descritivamente, por granulometria e composição mineralógica quantitativa, não obstante a idade e o modo de ocorrência geológica. Entretanto encontram-se também certos autores que adotam o modo de ocorrência como o critério principal (e.g. Hyndman, 1972).

Aspectos texturais de rochas ígneas têm uma relação com a estrutura geológica dos corpos ígneos. Rosenbusch (1877) apresentou uma correlação geral entre a estrutura de corpos ígneos e a granulometria de suas rochas constituintes: 1) rochas vulcânicas possuem granulometria fina e constituem corpos eruptivos tais como lava e tufo; 2) rochas hipabissais têm granulometria média e formam corpos intrusivos subvulcânicos, como dique e sill; 3) rochas plutônicas são de granulometria grossa e ocorrem como corpos plutônicos de grande profundidade, tal como batólito (Prancha 1A, coluna esquerda). Essa idéia foi amplamente aceita, até exageradamente, compondo uma importante base da petrologia de rochas ígneas nas aulas de graduação. Apesar da presença dessa tendência geral, a relação do ambiente geológico de corpos ígneos com a textura de suas rochas ígneas constituintes é, de fato, muito complexa (Prancha 1A, coluna direita).

Os vulcanólogos, em geral, têm forte interesse em fenômenos eruptivos. Portanto são atraentes os vulcões jovens, especialmente os ativos. As áreas com edifícios vulcânicos preservados geralmente não sofreram denudação regional, portanto os corpos subvulcânicos não estão expostos na superfície, daí serem relativamente pouco estudados.

Dessa forma, corpos subvulcânicos e suas rochas constituintes tendem a não chamar atenção dos vulcanólogos sob o ponto de vista petrológico, mineralógico e geoquímico, sendo que o pouco conhecimento levou certos corpos intrusivos de rochas piroclásticas a serem interpretados como edifícios vulcânicos (e.g. Ellert, 1959; Klein \& Vieira, 1980; Geraldes \& Netto, 2004; Mansur et al., 2004; Ferreira Neto, 2005).

Os problemas na interpretação geológica das rochas piroclásticas foram colocados em debate em várias ocasiões de congressos e simpósios (e.g. Motoki \& Oliveira, 1987; Motoki, 1988; Motoki et al., 1988; 2003b; 2004; 2005; Motoki \& Vargas, 2000). O presente trabalho apresenta um modelo didático sobre a relação entre a profundidade de cristalização dos corpos ígneos e as texturas de suas rochas constituintes conforme foi estabelecido através dos debates anteriormente citados, com a apresentação de exemplos do Brasil, Argentina e Chile.

\section{Edifícios vulcânicos}

Os vulcões ativos apresentam seus edifícios de forma quase original. Os estratovulcões desse estágio são encontrados na Cordilheira Chilena dos Andes, tais como Villarica (Prancha 2A, esquerda), Osorno, Llaima, Ronquimay (Moreno \& Gradeweg, 1989; Naranjo et al., 1992; Clavero \& Moreno, 2004; Moreno \& Fuentealba, 1994). Ocorrem, também, as caldeiras, tal como Hudson (Orihashi et al., 2004) e os domos, como Lautaro (Motoki et al., 2006), com sua morfologia eruptiva preservada. Na região norte da Patagônia Argentina, encontram-se cones piroclásticos (pyroclastic cone, cinder cone) do Quaternário quase sem efeito de erosão, tais como os cones do Parque Nacional Payún-Matru, Pata Mora (Prancha 2B, esquerda), Buta Ranquil e Auca Mahuida (González Díaz, 1969; Holmberg, 1976). Os exemplos similares são encontrados, também, na província vulcânica de Pali-Aike (D’Orazio et al. 2000; Corbella, 2002), extremo-sul da Patagônia Argentina. Alguns cones preservam a cratera no seu topo (Figura 1A). 


\section{Conceito tradicional}

Conceito atualizado

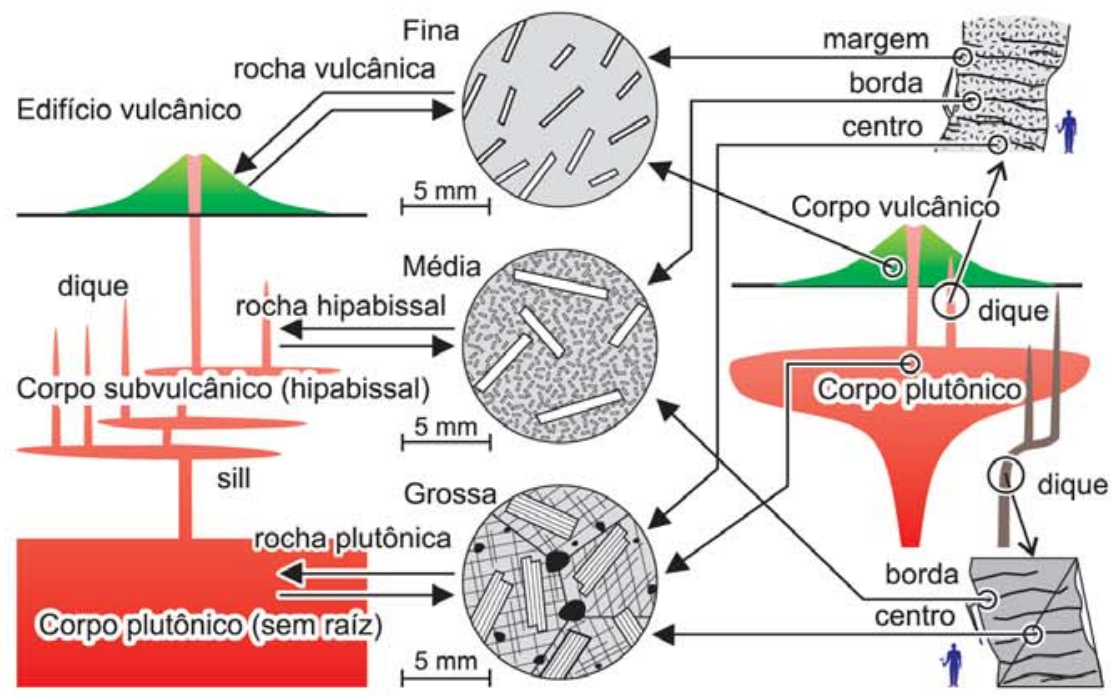

Prancha $1 \mathrm{~A}$ - Relação entre estrutura de corpos ígneos e textura de rochas ígneas conforme o conceito tradicional (coluna esquerda) e o conceito atualizado (coluna direita).

Vulcão sem denudação,

edifício vulcânico e derrames

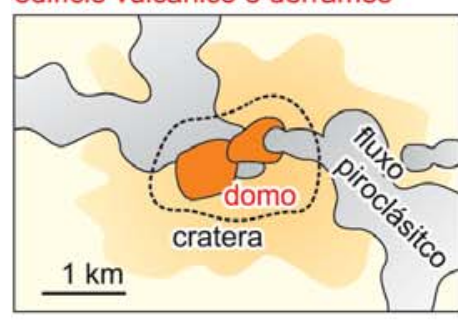

domo de lava colapso do domo

Denudação rasa ( 1 km), somente condutos vulcânicos

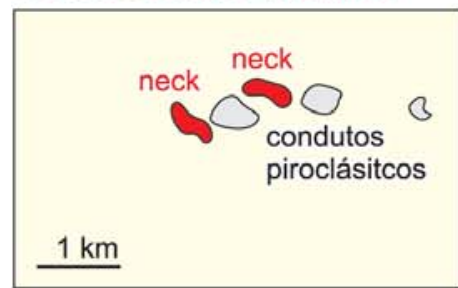

Denudação profunda ( $3 \mathrm{~km})$, corpo plutônico e condutos

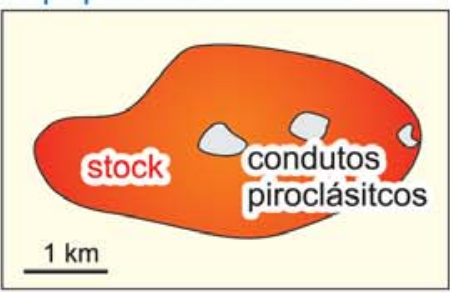

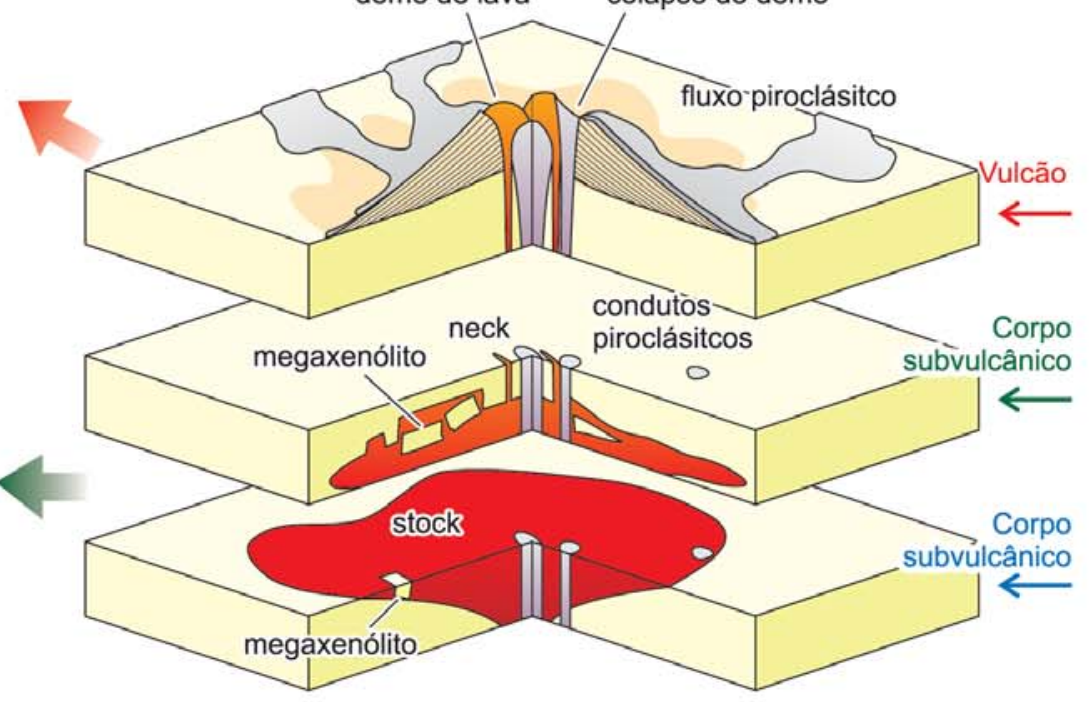

Corpo geológico

Rocha constituinte

tufo soldado

tufo e brecha soldado

traquito, fonolito, dacito

granito, sienito

traquito, fonolito, dacito, tufo

gnaisse e granito

Prancha 1B - Ilustração esquemática de correlação dos niveis de denudação (coluna esquerda) e respectivos mapas geológicos (coluna direita) de uma área de vulcanismo dacítico, conforme o nível de edifício vulcânico, estrutura subvulcânica, câmara magmática. 


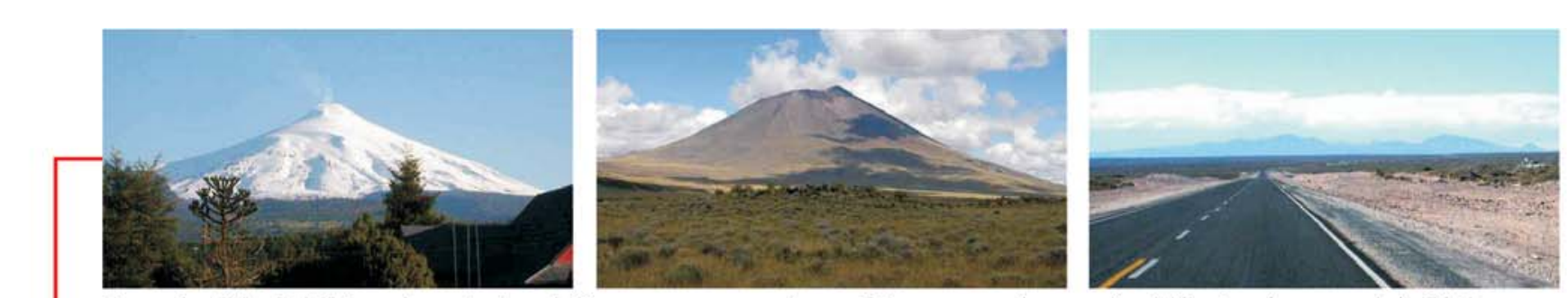

Prancha 2A-Edifícios de estratovulcões que apresentam vários graus de erosão: Villarica (esquerda), Chile, sem erosão; Payún, Mendoza, Patagônia Argentina norte, ligeiramente erodido (centro); Chachahuén, Mendoza, Patagônia Argentina norte, profundamente erodido (direita).
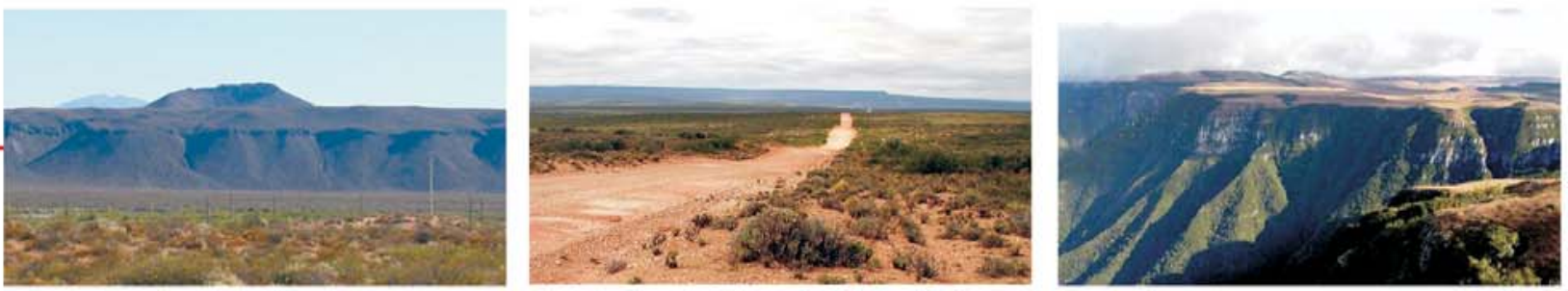

Prancha 2B - Áreas vulcânicas que estão em estágio inicial de denudação: Pata Mora, Mendoza, região norte da Patagônia Argentina (esquerda); Meseta de Somuncura, Rio Negro-Chubut, região nordeste da Patagônia Argentina (centro), Serra Geral, Vale do Rio do Rastro, Santa Catarina, Brasil (direita).
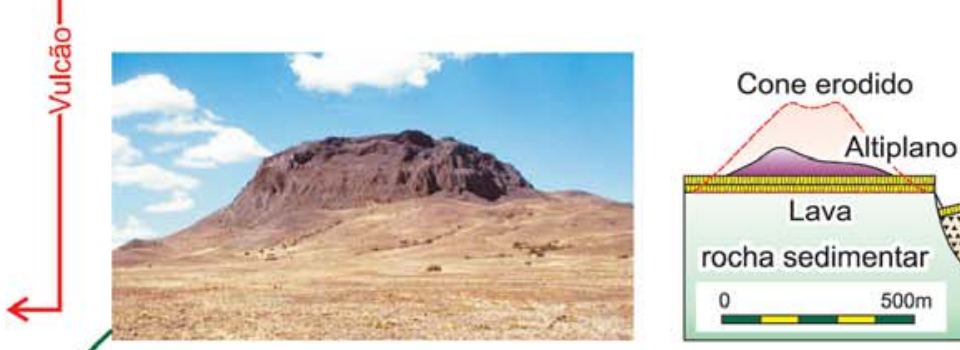

Superfície original

Prancha 2C - Cerro Redondo, Santa Cruz, região sul da Patagônia Argentina (esquerda) e o perfil esquemático desse corpo (direita), que apresenta seu modo de ocorrência geológica.
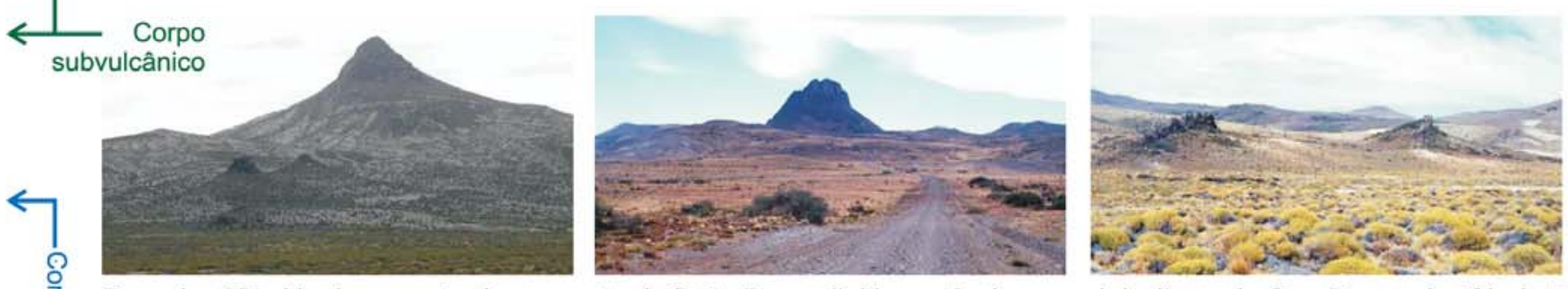

Prancha 2D - Neck encontrado ao oeste de Buta Ranquil, Neuquén (esquerda); dique de San Bernardo, Chubut (centro); neck presente ao norte do lago Cardiel, Santa Cruz (direita). Todos são da Patagônia Argentina.
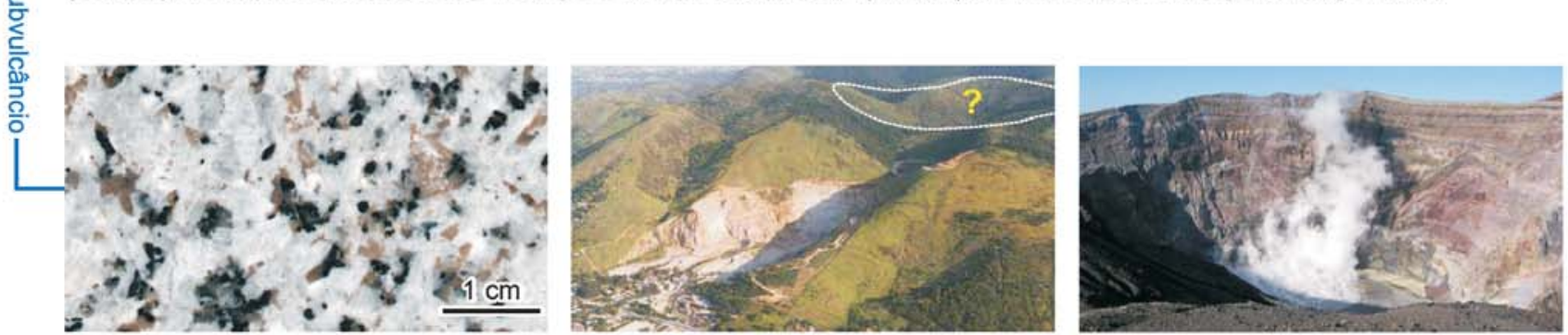

Prancha 2E - Textura do sienito da Mendanha, Rio de Janeiro, Brasil (esquerda); a morfologia interpretada como a cratera do Vulcão de Nova Iguaçu, Mendanha, por (Klein \& Vieira, 1980; área marcada com "?"; centro); a cratera vulcânica ativa do vulcão Aso, Kyûshû, Japão (direita). 
Com a passagem do tempo e conseqüente avanço da erosão, os vulcões perdem suas formas originais. Os estratovulcões do Plioceno da região norte da Patagônia Argentina, tais como Payún, em estágio inicial de erosão, (Prancha 2A, centro) e Cerro Nevado, em estágio mais avançado, são os exemplos (González Díaz, 1969; Holmberg, 1973). A erosão atuante, nesses vulcões, expõe corpos intrusivos dacíticos presentes dentro dos edifícios. Quando a erosão chega ao estágio muito mais avançado, o edifício vulcânico fica quase totalmente eliminado e a estrutura interna da parte inferior do edifício vulcânico fica exposta. O vulcão Chachahuén (Holmberg, 1962) da mesma região (Prancha 2A, direita) é um exemplo. Na Patagônia Argentina, ocorrem centenas de cones piroclásticos semi-erodidos, tais como aqueles do Plioceno da Meseta de Chenqueniyeu (Figura 1B) e os do Mioceno em torno de Maquinchao (Bjerg et al.,1998; Corbella, 1974; Gorring et al., 2003), ambos da Província de Río Negro. Os cones piroclásticos da parte sudeste da Província de Mendoza apresentam, didaticamente, o processo de degradação gradativa da morfologia original por erosão (Inbar \& Risso, 2001). Graças ao clima semidesértico, os cones e as lavas estão bem preservados. Sendo diferente do topo, a base dos cones piroclásticos é constituída por escória e spatter densamente soldados (Motoki et al., 2003a) e, portanto, resiste bem à erosão. Apesar das morfologias vulcânicas relativamente preservadas, as idades radiométricas das rochas constituintes são inesperadamente antigas. Por exemplo, o mapa geológico do Serviço Geológico da Argentina (SEGEMAR, 1994) interpretou o vulcão Trayen Niyeu, Província de Río Negro, como do Quaternário. Entretanto as datações K-Ar sem spike (método de sensibilidade) realizadas na Universidade de Tokyo, Japão, indicaram as idades do Mioceno, de 12.6 a 14.1 Ma (Orihashi et al., 2005).

No caso dos vulcões anteriormente citados, o nível da superfície atual é o mesmo da época de erupção. A elevação morfológica atual é atribuída, diretamen- te, ao acúmulo dos materiais eruptivos. As rochas que constituem os edifícios vulcânicos são de granulometria fina. Excepcionalmente, pequenos corpos intrusivos presentes nos edifícios vulcânicos podem ser compostos de rochas de granulometria média. Os contatos entre os corpos vulcânicos são suborizontais ou de baixo ângulo.

\section{Estágio inicial de denudação}

A erosão é o fenômeno supergênico que remove os materiais que constituem partes altas em relação à superfície regional, tal como edifícios vulcânicos. Por outro lado, a denudação remove os materiais, tanto dos vulcões, quanto da
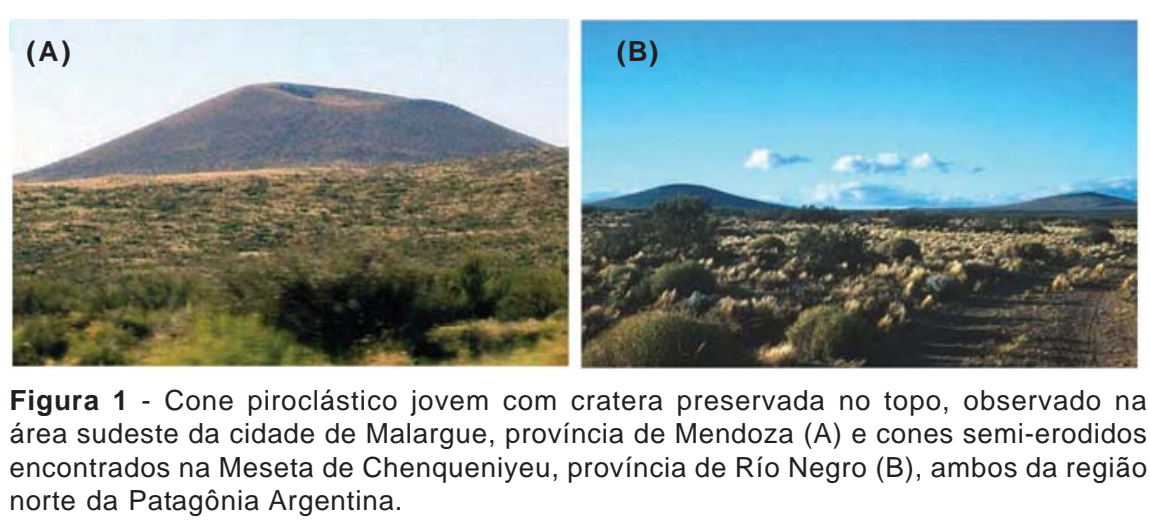

Figura 1 - Cone piroclástico jovem com cratera preservada no topo, observado na área sudeste da cidade de Malargue, província de Mendoza (A) e cones semi-erodidos encontrados na Meseta de Chenqueniyeu, província de Río Negro (B), ambos da região norte da Patagônia Argentina.

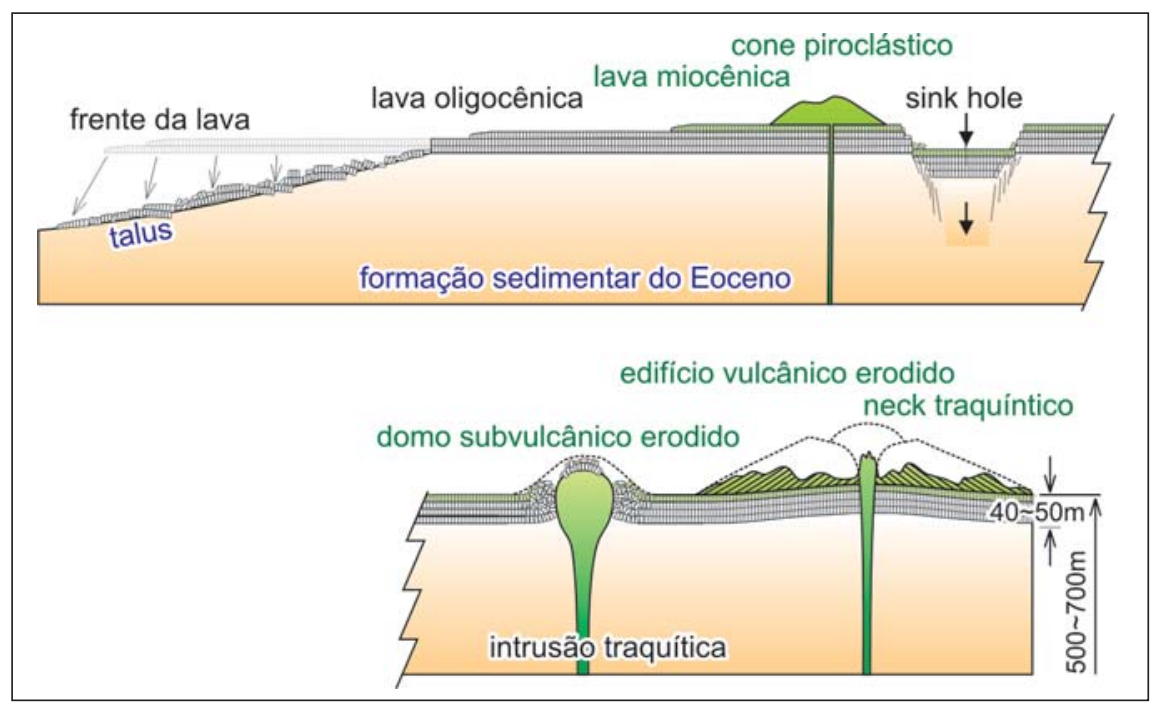

Figura 2 - Perfil esquemático do planalto basáltico da Meseta de Somuncura, províncias de Río Negro e Chubut, região nordeste da Patagônia Argentina, modificado a partir de Orihashi et al. (2005).

superfície regional (Prancha 2C, direita). Esse fenômeno ocorre por causa de abaixamento relativo do nível base da erosão, que é causado, comumente, por soerguimento regional.

As áreas vulcânicas que estão no estágio inicial de denudação preservam parcialmente, a superfície remanescente da época das erupções no topo do platô (Prancha 1B). O platô da Meseta de Somuncura (Prancha 1B, centro; Figura 2), região extra-retroarco do nordeste da Patagônia Argentina, é coberto por lavas basálticas do Oligoceno e Mioceno (Remesal et al., 2002; Orihashi et al., 2005). Os edifícios vulcânicos se salientam no topo do platô e as estruturas subvulcânicas estão expostas nas paredes laterais.

REM: R. Esc. Minas, Ouro Preto, 59(1): 13-23, jan. mar. 2006 
No Vale do Rio do Rastro, Santa Catarina, Brasil, encontra-se um exemplo similar (Prancha 2B, direita; Motoki et al., 2003b). As lavas basálticas constituem o platô da Serra Geral (Peate et al., 1990; 1992) e um sill subvulcânico está exposto na parede lateral da escarpa. A preservação do platô basáltico é devido à alta resistência das lavas à erosão. Por causa da permanência parcial do platô, essa ocorrência pode ser classificada como um vulcão de lato sensu. Entretanto não está sendo tratado de tal forma por causa da idade antiga, do início do Cretáceo (Stewart et al., 1996).

Nesses exemplos, o edifício vulcânico é composto de rochas de granulometria fina, porém os corpos subvulcânicos são constituídos por rochas de granulometrias variáveis, sendo grossa, média e fina. Os contatos dos corpos vulcânicos são suborizontais e aqueles dos corpos subvulcânicos são geralmente subverticais. Entretanto certos corpos subvulcânicos, tal como o sill, têm contato suborizontal, podendo ser confundidos com a lava (Motoki et al., 2003a; b).

\section{4. Áreas denudadas}

Nas áreas onde a denudação é mais avançada, o edifício vulcânico é quase totalmente eliminado e a estrutura subvulcânica está amplamente exposta na superfície. Os exemplos desse estágio, caracterizados pela coexistência de edifício vulcânico e corpo subvulcânico, são raros no mundo, porém se encontram no vale do Río Chico, região sul da Patagônia Argentina (Motoki et al., 2003a; Shilling et al., 2005). Nesse vale, ocorrem Cerro Redondo (Prancha 2C, esquerda) e Cerro Ventana. O topo desses morros é composto de spatter e escória soldados, correspondendo à base de cone piroclástico. Logo abaixo disso, ocorre uma camada composta de basalto maciço de espessura mínima de $50 \mathrm{~m}$. Na ocasião de trabalho de campo, realizado em janeiro e fevereiro de 2001, foi observado que as lavas álcali-olivina basálticas dessa região, relativas ao magmatismo das ocorrências citadas anteriormente, têm espessura média de $6 \mathrm{~m}$. Portanto a es- pessura de $50 \mathrm{~m}$ é grande demais para ser considerada a de uma lava. Além disso, não se observam estruturas características de aa lava, que é um tipo comum de lava basáltica de erupção subaérea com espessura relativamente grande, tais como paleossolo da formação inferior, $a a$ clinker na parte inferior da lava, $a a$ clinker da parte superior e entablature.

"Aa clinker" corresponde às camadas constituídas por fragmentos porosos de basalto originados do processo de alto-brechação, que se encontram na parte superior e inferior de um fluxo de a lava. "Entablature" é o nível composto de disjunções de diâmetro decimétrico e diaclasamentos de curto intervalo que ocorrem sobre o colonade, o nível composto de disjunções colunares de diâmetro métrico (Figura 3). Dessa forma, esse corpo geológico não é interpretado como uma lava, sendo um sill de intrusão extremamente rasa (Motoki et al., 2003a; 2003b; 2004; 2005). Esses afloramentos mostram que, em alguns casos, a câmara magmática pode ocorrer logo abaixo de cone piroclástico.

Quando a denudação é mais avançada, o edifício vulcânico fica completamente eliminado. Dessa forma, são expostos somente corpos subvulcânicos, tais como dique, sill e neck (Prancha 2D; Ramos, 1982; Holmberg, 1976). Sem edifício vulcânico remanescente, a profundidade da intrusão, ou seja, o nível de denudação, é difícil a ser estimada. Essa pode ser inferida somente por meio de estudos geomorfológicos regionais e datação de traço de fissão para apatita (e.g. Zimbres et al., 1990). Com a exceção de sill, os planos de contato são subverticais e a granulometria das rochas constituintes varia em função de tamanho do corpo intrusivo.

Quando a denudação chega ao nível da câmara magmática, aparecem corpos plutônicos constituídos por rochas de granulometria grossa (Prancha 2E, esquerda). Nas regiões litorâneas dos Estados de São Paulo e Rio de Janeiro, ocorrem dezenas de corpos sieníticos, que correspondem às câmaras magmáticas do Cretáceo, tais como da Ilha de
Vitória (Motoki, 1986), Poços de Caldas (Motoki \& Oliveira, 1987; Motoki, 1988; Motoki et al., 1988), Mendanha (Prancha 2E, centro; Motoki et al., 2005; Silveira et al., 2005) e Itatiaia (Brotzu et al., 1997).

A profundidade da câmara magmática é variável. As mais rasas estão na profundidade subsuperficial, que estão em contato com a base do edifício vulcânico (Prancha 2C, direita). Uma pesquisa sismológica revelou que o Vulcão Katmai, do Alaska, tem duas câmaras magmáticas de forma discóide, uma em alguns quilômetros de profundidade e outra, a mais de $20 \mathrm{~km}$ (Matsumoto 1971). As câmaras magmáticas ativas, identificadas por meios geofísicos, apresentam freqüentemente, sua forma achatada, como um sill, e os contatos com a rocha encaixante são de baixo ângulo.

Até mesmo no caso de um corpo intrusivo raso, quando este tem tamanho suficientemente grande, a parte central é constituída por rochas de granulometria grossa, classificando-se como rochas plutônicas. A granulometria de rochas ígneas é relacionada à taxa de resfriamento do magma, que é controlado, também, pelo tamanho do corpo magmático (Motoki, 2004). No caso de corpos intrusivos rasos, o efeito de tamanho do corpo magmático é expressivo. Os diques espessos, com largura superior a $4 \mathrm{~m}$, que ocorrem no Estado do Rio de Janeiro, são compostos de rochas de granulometria variável, que se classificam como basalto, dolerito e gabro (Figura 4). Sem dúvida, a profundidade de intrusão dessas rochas é a mesma. A datação traços de fissão para apatita sugere uma profundidade de 4 a $5 \mathrm{~km}$ (Zimbres et al., 1990).

\section{Corpos piroclásticos}

Dentro de um corpo ígneo, observa-se, comumente, uma variação litológica. Certas partes de corpos intrusivos subvulcânicos são constituídas por rochas de granulometria fina, com a mesma textura das rochas constituintes de 
uma lava. No caso de rochas piroclásticas soldadas (welded pyroclastic ro$c k s$ ), tais como lapilli, brecha e aglomerado, esse fenômeno é muito expressivo. Há um grande número de exemplos de tufo soldado que não ocorre como fluxo piroclástico, mas como de preenchimento de condutos vulcânicos (e.g. Motoki, 1979; 1988). Sendo assim, é difícil distinguir, a partir de descrições litológicas e petrográficas, se a rocha é componente de um fluxo piroclástico ou de preenchimento de um conduto vulcânico.

Os corpos sieníticos da região Sudeste do Brasil são acompanhados, freqüentemente, por rochas piroclásticas densamente soldadas, chamados popularmente de "brecha vulcânica", tais como os de Poços de Caldas, Itatiaia, Mendanha e Ilha de Cabo Frio. Algumas dessas foram interpretadas como depósitos de fluxo piroclástico (e.g. Ulbrich, 1984; Klein \& Vieira, 1980) ou conglomerado sedimentar com seixos de rochas vulcânicos (e.g. Ellert, 1959). A matriz das brechas é totalmente consolidada. Considerando a idade cretácica, essa consolidação não pode ser atribuída à diagênese do conglomerado sedimentar, mas, sim, ao soldamento de rochas piroclásticas.

Rochas piroclásticas ocorrem, tanto como corpos extrusivos, tal como fluxo piroclástico, quanto como corpos intrusivos, de preenchimento de condutos e fissuras vulcânicos. $\mathrm{O}$ arredondamento dos clastos e a seleção granulométrica ocorrem durante a flutuação dos fragmentos dentro do conduto (Figura 5A). A textura de acamamento é formada por meio de deformação plástica durante a compactação pelo soldamento e fluxo secundário da matriz, que é composta de pó de vidro vulcânico (Figura 5B). O soldamento e o fluxo secundário dos depósitos piroclásticos de preenchimento de condutos e fissuras vulcânicos se desenvolvem mais intensamente do que aqueles de fluxos piroclásticos (Motoki, 1979; 1988; Motoki et al., 1988).

Dessa forma, o modo de posicionamento geológico de rochas piroclásticas

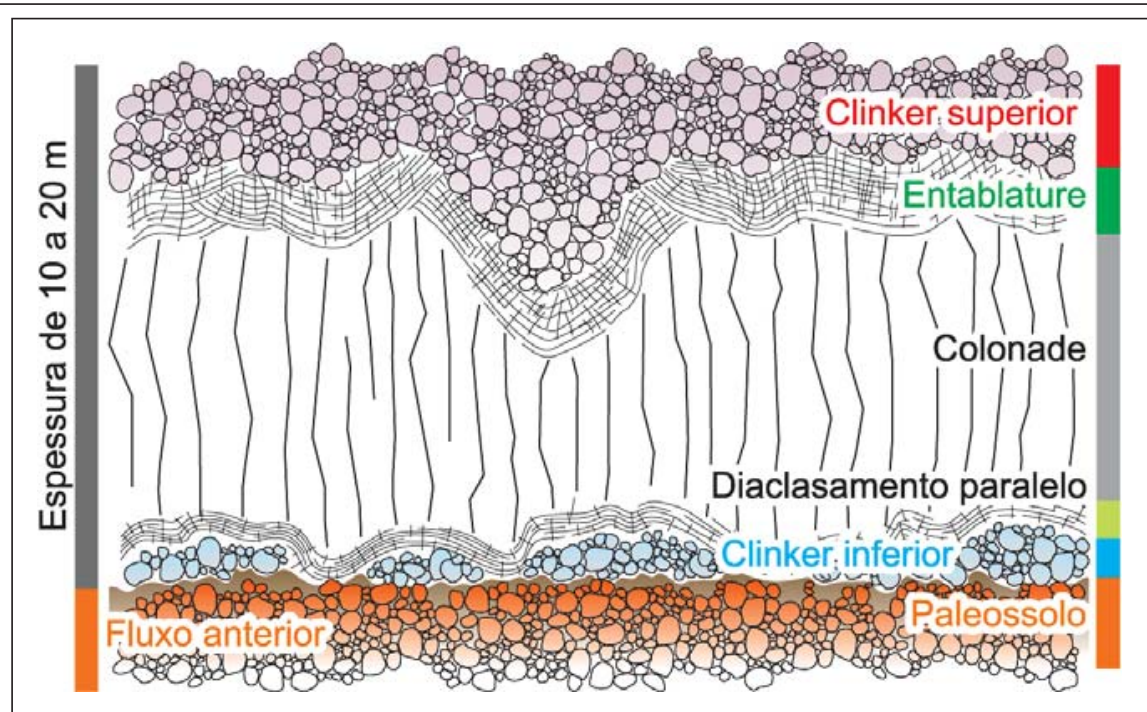

Figura 3 - Perfil esquemático da estrutura interna de um fluxo de aa lava, apresentando relação entre clinker inferior, diaclasamento paralelo (basal plenty joint), colonade, entablature e aa clinker superior. O nível abaixo de clinker inferior é o paleossolo originado da lava basáltica anterior. O tamanho dos blocos que constituem clinkers é exagerado relativo à espessura da lava, de 10 a 20 m. A presente ilustração foi elaborada com base na modificação de Motoki et al. (1999).

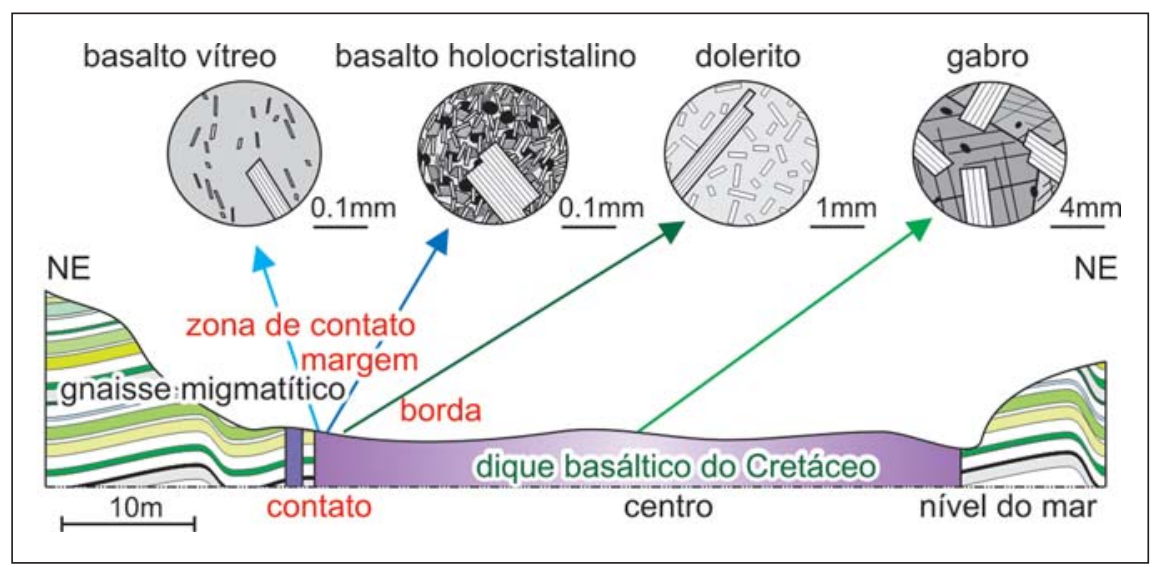

Figura 4 - Rochas constituintes de um dique no Clube Costa Brava, Rio de Janeiro, Brasil, variando de basalto vítreo na zona de contato, basalto hialocristalino na margem, dolerito holocristalino na borda e gabro no centro. Nota-se que as escalas das ilustrações esquemáticas de aspectos microscópicos não são iguais.

deve ser determinado, exclusivamente, por meio de observações de campo, sobretudo de afloramentos de contato. Os corpos extrusivos têm extensão horizontal grande, espessura pequena e planos de contato suborizontais. Certos fluxos piroclásticos têm extensão horizontal de centenas de quilômetros (e.g. Milner et al. 1995). Por outro lado, os condutos e fissuras vulcânicos de rochas piroclásticas têm extensão horizontal pequena, dimensão vertical grande e os planos de contato subverticais. A extensão horizontal dos corpos piroclásticos intrusivos é normalmente inferior a $1 \mathrm{~km}$. Existem pequenas fissuras vulcânicas que aparecem como diques de largura métrica, que são preenchidas por materiais piroclásticos altamente soldados (Figura 6). Entretanto não se encontrou um sill piroclástico.

O corpo piroclástico que ocorre na margem nordeste do complexo intrusivo 
sienítico da Mendanha, Rio de Janeiro, era considerado como um edifício vulcânico, chamado, popularmente, de Vulcão de Nova Iguaçu (e.g. Klein \& Vieira, 1980; Geraldes \& Netto, 2004; Mansur et al., 2004; Ferreira Neto et al., 2005; Silveira et al., 2005). Entretanto, conforme os critérios citados anteriormente, essa ocorrência é classificada como sendo um corpo subvulcânico que corresponde a conduto vulcânico (Motoki et al., 2005; Mota \& Geraldes, 2005). O perfil vertical de um edifício vulcânico apresenta a estratificação composta de lavas e depósitos piroclásticos (Prancha 2E, direita). Porém o perfil do corpo de Nova Iguaçu mostra aspecto maciço de álcali sienito (Prancha $2 \mathrm{E}$, centro). A localidade interpretada como a cratera vulcânica com base na fotointerpretação (Klein \& Vieira, 1980) possui uma estrutura geológica incompatível (Silveira et al., 2005). O perfil geológico dessa região mostra que o nível de denudação atual corresponde à base da câmara magmática do magma sienítico (Figura 7). As datações preliminares de traços de fissão para apatita sugerem uma denudação regional de 3 a 4km (Zimbres et al., 1990).

\section{Discussão}

Os exemplos anteriormente citados indicam que, até mesmo na condição semidesértica da Patagônia Argentina, não se encontra um edifício vulcânico de ida-

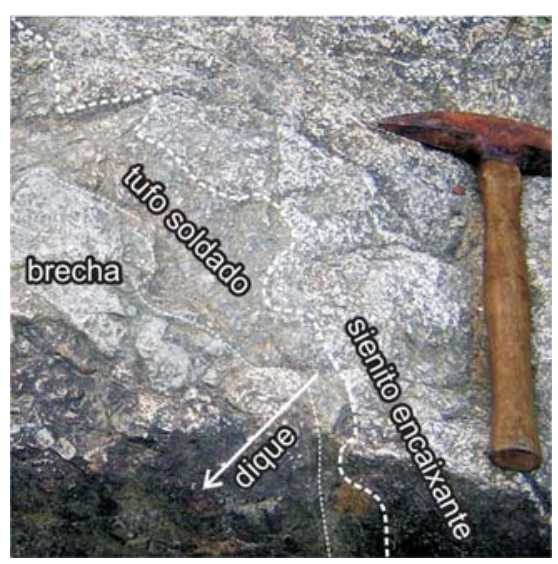

Figura 6 - Dique constituído por brecha soldada e tufo soldado, de largura de $2 \mathrm{~m}$, Mendanha, Nova Iguaçu, Rio de Janeiro, Brasil.

\section{Durante a erupção \\ Durante o soldamento}

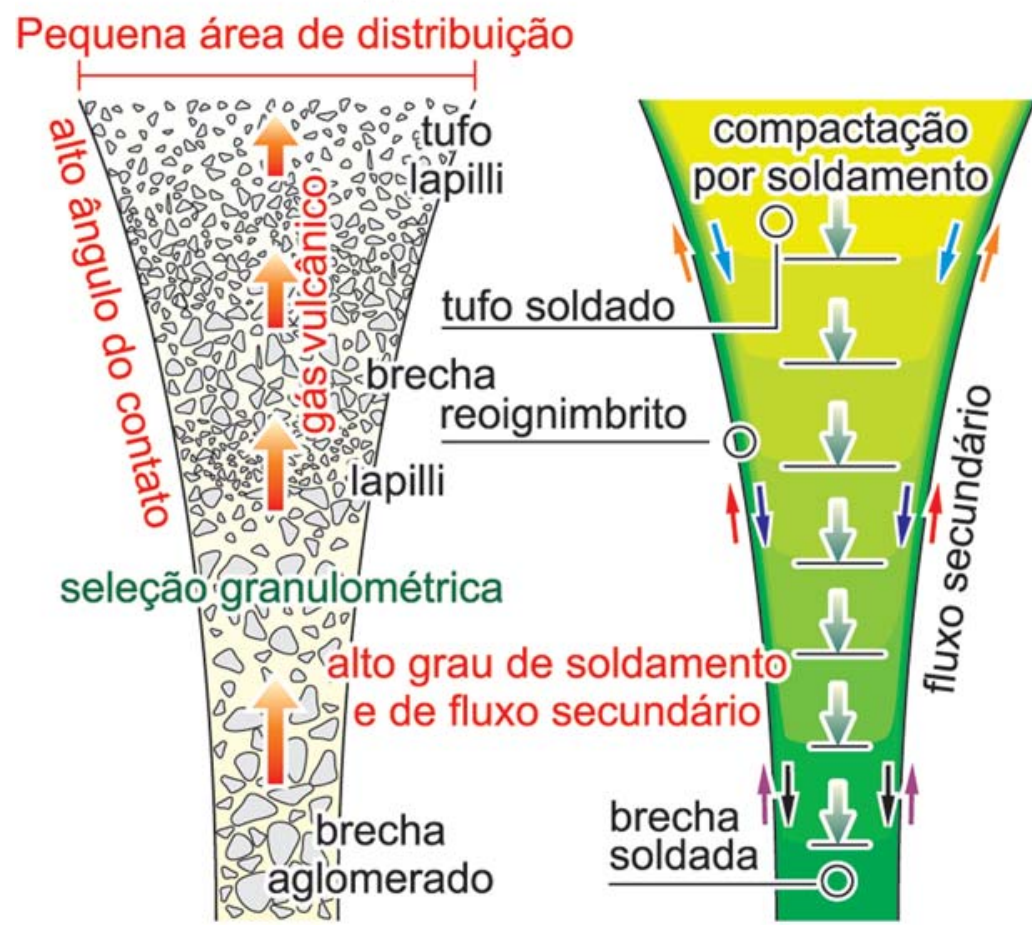

Figura 5 - Processo de seleção granulométrica por meio de gás vulcânico durante a erupção $(A)$ e de formação de textura de acamamento por soldamento e fluxo secundário (B), dos materiais piroclásticos de preenchimento de conduto vulcânico. A expressão "reoignimbrito", utilizada nessa figura, representa apenas características litológicas da rocha e não o modo de ocorrência geológica.

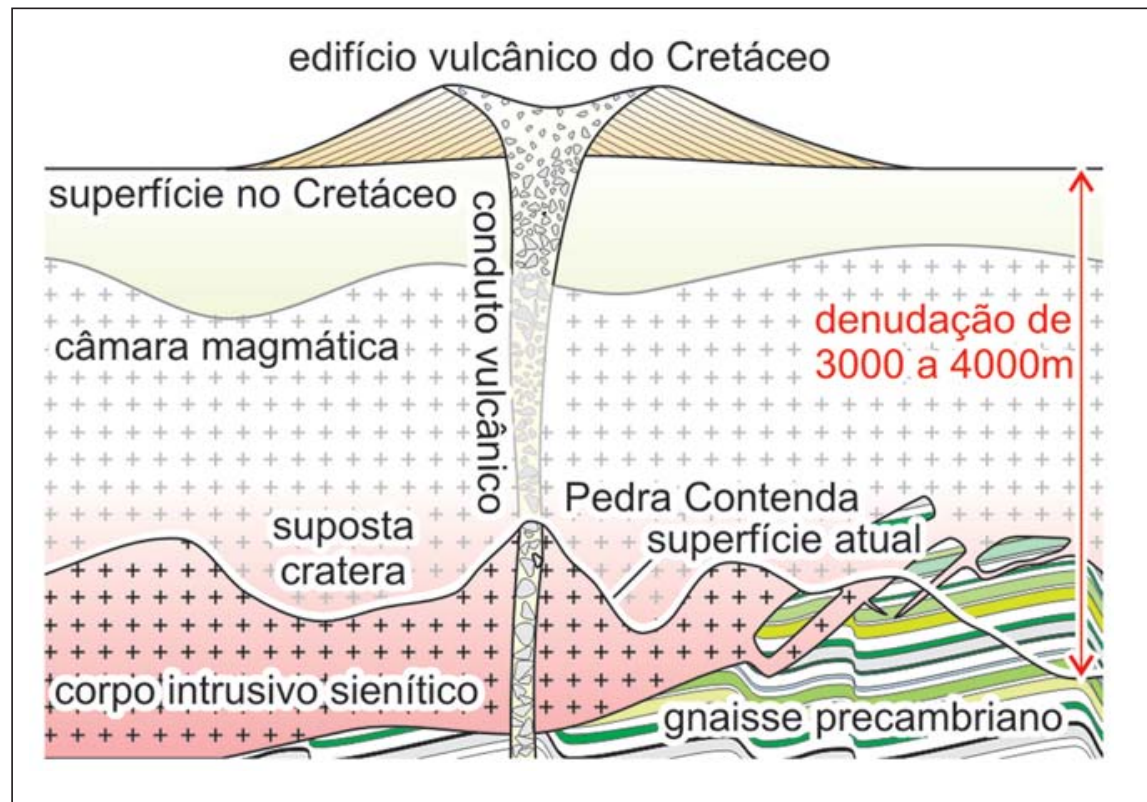

Figura 7 - Perfil geológico esquemático da parte nordeste do Complexo Sienítico da Mendanha, Nova Iguaçu, RJ, modificado de Motoki et al. (2005), apresentando o modo de ocorrência geológico do Corpo Piroclástico da Pedra de Contenda, Cretáceo, e da zona de contato inferior da câmara magmática sienítica, também de intrusão cretácica. O relevo da superfície atual é exagerado em 3 vezes relativo ao nível de denudação e em 10 vezes relativo à escala horizontal. 
de mais antiga do que o Oligoceno. No Brasil, sob a condição climática tropical da região litoral e da Amazônia, o efeito da erosão é, incomparavelmente, maior do que nas regiões áridas. Devido a isso, é inviável a preservação dos edifícios vulcânicos com presença de cratera, caldeira ou domo de idade mesozóica (e.g. Ellert ,1959; Klein \& Vieira, 1980) ou das eras anteriores (Knapp, 2002). Na região de Isua, Groenlândia, ocorre uma pillow lava de 3,7 a 3,8 Ga, que constituía um edifício vulcânico submarino (Komiya et al., 1999). Esta é a rocha vulcânica mais antiga do Planeta Terra com comprovação geológica e, obviamente, não há morfologia remanescente do edifício vulcânico.

Por outro lado, na condição climática extremamente árida do Planeta Marte, encontra-se uma dúzia de vulcões de idade precambriana bem preservados. $\mathrm{Na}$ região de planalto de Tharsis, existem vulcões com altura superior a $10.000 \mathrm{~m}$, tais como Olympus Mons, Ascreus Mons, Pavonis Mons e Arsia Mons. Segundo os estudos da cronologia de crateras (crater chronology), a formação desses vulcões começou no Nochiano (4,6 a 3,5 Ga), que corresponde ao tempo geológico da Terra a partir do Hadeano ao início do Arqueano, e os edifícios vulcânicos chegaram ao tamanho atual no Hesperiano (3,5 a 1,8 Ga), correspondente ao período a partir do Arqueano ao Proterozóico médio (e.g. Carr ,1975; Greeley \& Spudis, 1981).

Apesar da inexistência de vulcões, na região continental do Brasil ocorrem muitos corpos subvulcânicos. Estes fornecem importante informação sobre os fenômenos de atividades magmáticas abaixo dos vulcões (e.g. Phillips, 1974; Haimson, 1975; Motoki, 1979; 1988; 1994; Motoki \& Oliveira, 1987; Feraud \& Campredon, 1983; Laughlin et al., 1983; Motoki \& Vargas, 2000; Motoki et al., 1988). Nesse sentido, os geólogos do Brasil têm a potencialidade de realizar importantes contribuições ao desenvolvimento da vulcanologia mundial.

\section{Conclusão}

Os exemplos dos corpos ígneos e suas rochas constituintes do Brasil, Argentina e Chile apresentam freqüentes ocorrências de corpos intrusivos rasos constituídos por rochas de granulometria fina, classificada como "rochas vulcânicas”, e também de granulometria grossa, "rochas plutônicas". Além disso, a relação dos corpos ígneos com sua profundidade de posicionamento também não é simples. A Prancha 1B apresenta uma relação geral entre os níveis de denudação de uma área vulcânica e os modelos do mapa geológico regional. Somente a ocorrência do nível sem denudação pode ser chamada de vulcão.

Dessa forma, a dedução de modo de ocorrência geológica e profundidade de posicionamento, a partir da textura de uma rocha ígnea, deve ser limitada. As expressões rochas vulcânicas, hipabissais e plutônicas devem ser utilizadas com cuidado, sendo preferível apenas para descrição granulométrica nas observações petrográficas. Para a classificação de rochas ígneas, as expressões "granulometria fina", "média” e "grossa" são mais recomendadas. Os termos "extrusivo", "vulcânico", "subvulcânico", "hipabissal”, "intrusivo” e "plutônico" devem ser utilizados, exclusivamente, para descrições geológicas de corpos ígneos.

O modo de ocorrência de corpos ígneos deve ser determinado por meio de observação dos afloramentos, sobretudo do contato entre corpos geológicos, e não por dedução, a partir das observações litológicas e petrográficas, ou por simples fotointerpretação.

\section{Agradecimentos}

As imagens dos vulcões e corpos subvulcânicos da Patagônia Argentina foram obtidas durante os trabalhos de campo relativos ao Projeto "Chile Kaikô shizumicomi to rikukogawa ni okeru kaseikatudô no jikûteki hensen”, Processo 13373004, do Ministério de Educação e Ciência do Governo Japonês. Os autores agradecem ao Dr. Yuji Orihashi, Ear- thquake Research Institute of the University of Tokyo, Japão, o chefe do grupo da vulcanologia e ao Dr. Ryo Anma, Universidade de Tsukuba, Japão, chefe geral do projeto.

\section{Referências bibliográficas}

BATES, R., JACSON, J.A. Glossary of Geology, 3rd edition. McGraw-Hill Book Company, 1987. 788p.

BJERG, E.A., GREGORI, D.A.. LABUDIA, C.H. Geología de la región del El Cuy, Macizo de Somuncurá, provincia de Río Negro. Revista de la Asociación Geológica Argentina, v. 52, n. 3, p. 387-399, 1998.

BROTZU, P., GOMES, C. B., MELLUSO, L., MORBIDELLI, L., MORRA, V., RUBERTI, E. Petrogenesis of coexisting $\mathrm{SiO}_{2}$-undersaturated to $\mathrm{SiO}_{2}$-oversaturated felsic igneous rocks: the alkaline complex of Itatiaia, southern eastern Brazil. Lithos, v. 40, p. 133-156, 1997.

CARR M. H. The Volcanoes of Mars. Scientific American, v. 234, p. 32-43, 1975.

CLAVERO, J., MORENO, H. Evolution of Villarica Volcano. Boletín de Servicio Nacional de Geología y Minería, Gobierno de Chile, v. 61, p. 17-27, 2004.

CORBELLA, H. Contribución al conocimiento geológico de la Alta Sierra de Somuncura, Macizo Nordpatagónico, provincia de Río Negro (República Argentina). Revista de la Asociación Geológica Argentina, v. 29, n. 2, p. 155-190, 1974.

CORBELLA, H. El campo volcano-tectónico de Pali Aike. In: HALLER, M.J. (ed.). Geología y Recursos Naturales de Santa Cruz. Relatorio del $\mathrm{XV}^{\circ}$ Congreso Geológico Argentino. El Calafate. Buenos Aires, p. 287-303, 2002.

D’ORAZIO, M., AGOSTINI, S., MAZZARINI, F., INNOCENTI, F., MANETTI, P. HALLER, M.J., LAHSEN, A. The Pali Aike Volcanic Field, Patagonia: slabwindow magmatism near the tip of South America. Tectonophysics, v. 321, p. 407427, 2000.

ELLERT, R. Contribuição geológica do maciço alcalino de Poços de Caldas. Bol. Fac. Fils. Ci. Let. Universidade de São Paulo, v. 237, Geologia n. 18, p. 1-64, 1959.

FERAUD, G., CAMPREDON, R. Geochronology and structural study of Tertiary and Quartenary dikes in southern France and Sardinia: An example of utilization of dike swarms as paleostress indicators. Tectonophysics, v. 98, p. 297325, 1983.

FERREIRA NETO, W.D., PIMENTEL, L.S., SILVA, F.L., GAYER, V., GERALDES, M.C. Estudos geológicos e petrográficos 
Avaliação de aspectos texturais e estruturais de corpos vulcânicos e subvulcânicos e sua relação...

de gerações de traquitos no complexo alcalino do Mendanha, Nova Iguaçu-RJ. Boletim de Resumos de $9^{\circ}$ Simpósio de Geologia do Sudeste, $13^{\circ}$ Simpósio de Geologia de Minas Gerais, CD, 2005.

GERALDES, M.C., NETTO, A.N. Elaboração de placas do Geoparque do Vulcão de Nova Iguaçu-RJ: a utilização de linguagem popular para explicar a construção de um edifício vulcânico. In: CONGRESSO BRASILEIRO DE GEOLOGIA, 42. Anais..., 1 p, CD, 2004.

GONZÁLEZ DÍAZ, E.F. Un puente natural en el ambiente lávico oriental del volcán Payún- Matru, Pcia. de Mendoza. Revista de Asociación Geológica Argentina, v. 24, n. 2, p. 85-89, 1969.

GORRING, M., SINGER, B., GOWERS, J., KAY, S.M. Plio-Pleistocene basalts from the Meseta del Lago Buenos Aires, Argentina: evidence for asthenosphere-lithosphere interactions during slab window magmatism. Chemical Geology, v. 193, p. 215-235, 2003.

GREELEY R., SPUDIS, P. D. Volcanism on Mars. Reviews of Geophysics and Space Physics, v. 19, p. 13-41, 1981.

HAIMSON, B.C. Deep in-situ stress measurements by hydrofracturing. Tectonophysics, v. 29, p. 41-47, 1975.

HATAYAMA, Y. e 344 coautores. Chigaku Jiten (Geological Dictionary). Tokyo: The Association for Geological Collaboration, 1980. 1612 p. (em Japanês).

HOLMBERG, E. Descripción de la Hoja 32d Chachahuén, Provincias de Neuquén y Mendoza. Dirección Nacional de Geología y Minería, Boletín n. 91, Republica Argentina, p. 1-70, 1962.

HOLMBERG, E. Descripción geológica de la hoja 29d, Cerro Nevado. Pcia. de Mendoza. Dirección Nacional de Geología y Minería, Republica Argentina, 1973.

HOLMBERG, E. Descripción geológica de la Hoja 32c, Buta Ranquil. Pcia. de Neuquén. Boletín de Servicio Servicio Geológico Minero Argentino, n. 152, 1976.

HYNDMAN, D.W. Petrology of igneous and metamorphic rocks. McGraw-hill Book Company, 1972. 533p.

INBAR M., RISSO C. A morphological and morphometeric analysis of a high density cinder cone volcanic field - Payun Matru, south-central Andes, Argentina. Zeit Geomorph, Leipzig, Deutschland, v. 45, p. 321-343, 2001.

JOHANNSEN A. A descriptive petrography of the igneous rocks, vol. I. Introduction, textures, classification and glossary. Univ. Chicago Press, 1939. 318 p.

KLEIN, V.C., VIEIRA, A.C. Vulcões do Rio de Janeiro: breve geologia e perspectivas. Mineração Metalurgia, v. 419, p. 44-46, 1980.

KNAPP, L. Amazônia abriga vulcão mais antigo do mundo. $C \&$ T Jovem, Ministério de
Ciência e Tecnologia. 2002. http:// ctjovem.mct.gov.br/index.php?action=/ content $/$ view\&cod objeto=8329.

KOMIYA, T., MARUYAMA, S., MASUDA, T., NOHDA, S., HAYASHI, M., OKAMOTO, K. Plate tectonics at 3.8$3.7 \mathrm{Ga}$ : field evidence from the isua accretionary complex, Southern West Greenland. Jour. Geol. v. 107, n. 5, p. 515554, 1999.

LAUGHLIN, A.W., ALDRICH, M.J., VANIMAN, D.T. Tectonic implications of mid-Tertiary dikes in west-central New Mexico. Geology, v. 11, p. 45-48, 1983.

MACDONALD, G.A. Volcanoes. PrenticeHall, Englewood Cliffs, 1972. 510 p.

MANSUR, K., GHIZI, A., GUEDES, E., MEDEIROS, F., NOGUEIRA, G., BARBOSA, M. A transformação da linguagem científica em popular na elaboração de placas descritivas de pontos de interesse geológico: o caso do Geoparque do Vulcão de Nova Iguaçu. In: CONGRESSO BRASILEIRO DE GEOLOGIA, 42. Anais..., 1 p, CD, 2004.

MATSUMOTO, T. Seismic body waves observed in the vicinity of Mount Katmai, Alaska, and evidence for the existence of molten chambers. Geol. Soc. Amer. Bull. v. 82, p. 2905-2920, 1971.

MILNER, S.C., DUNCAN, A.R., EWART, A. Trans-Atlantic correlation of eruptive sequences and individual silicic volcanic units within the Paraná-Etendeka igneous province. Journ. Volcanol. Geotherm. Res. v. 69, p. 137-157, 1995.

MORENO, H., FUENTEALBA, G. The May 17-19, 1994 Llaima volcano eruption, southern Andes (384' $\mathrm{S}$ - $71^{\circ} 44^{\prime} \mathrm{W}$ ). Revista Geológica de Chile, v. 21, n. 1, p. 167-171, 1994.

MORENO, H., GRADEWEG, M. La erupción reciente en el Complejo Volcánico Lonquimay (Deciembre, 1988), Andes del Sur. Revista Geológica de Chile, v. 16, p. 93-117, 1989.

MOTA, C.E., GERALDES, M.C. As brechas tectônicas no maciço do Mendanha, Nova Iguaçu - RJ: registros de processos de colapso por pressão de magma. In: SIMPÓSIO DE VULCANISMO E AMBIENTE ASSOCIADOS, 3. Anais..., p. 381-386, 2005.

MOTOKI, A. A possible fossil earthquake swarm? - Relationship between Mesozoic basaltic dykes and their linkage faults. Jour. Geography, v. 103, n. 3, p. 548-557, 1994.

MOTOKI, A. An outline about problems of volcanic caldera hypothesis of the Poços de Caldas Alkaline Complex Rock Body, Minas Gerais - São Paulo, Brazil. In: CONGRESSO LATINOAMERICANO DE GEOLOGIA, 7. Anais..., v. 1, p. 309-323. 1988.

MOTOKI, A. Cretaceous volcanic vents in southeast part of Mt. Rokko, western
Honshu, Japan. Bull. Volcanological Society of Japan, Second Series, v. 24, n. 2, p. 55-72, 1979. (Em japonês).

MOTOKI, A. Descrição petrográfica de rochas ígneas. DMPI/UERJ, 96 p. 2004.

MOTOKI, A. Geologia e petrologia do Maciço Alcalino da Ilha de Vitória, SP. São Paulo: Instituto de Geociências da Universidade de São Paulo, 1986. (Inédito) (Tese de Doutorado).

MOTOKI, A., ADRIANO, L., MELO, D.P., FREITAS, A. Edifícios vulcânicos e corpos subvulcânicos, de acordo com os níveis de denudação: exemplos do Brasil e da Argentina. In: CONGRESSO BRASILEIRO DE GEOLOGIA, 42. Anais..., 1 p, CD, 2004.

MOTOKI, A., OLIVEIRA, J.L.S. Reconsiderações vulcanológicas sobre a hipótese de caldeira vulcânica no Complexo Alcalino de Poços de Caldas, MG. Parte I: Rochas sedimentares como corpos capturados, fragmentados e afundados no magma fonolítico. In: SIMP. GEOL. MINAS GERAIS, 4. Anais..., p. 240-243, 1987.

MOTOKI, A., ORIHASHI, Y., HIRATA, D., HALLER, M.J., HOSONO, T., CARIO, F.D., SHILLING, M., ANMA, R. Monogenic volcanoes of back-arc province, southern Argentina. Journal of the Geological Society of Japan, v. 109, n. 7, p. XIII-XIV, 2003a.

MOTOKI, A., SICHEL, S., FONCECA, L.G., SILVA, M.S., ALMEIDA, F.S.S., CORRALES, F. Relação entre as texturas de rochas vulcânicas e estruturas de corpos vulcânicos e subvulcânicos: exemplos do Brasil, Argentina e Chile. In: SIMPÓSIO DE VULCANISMO E AMBIENTES ASSOCIADOS, 3. Anais..., p. 387-392, 2005.

MOTOKI, A., VARGAS T., CHIANELLO E., CORRÊA, F.J.G., OLIVEIRA, J.L.S., KLOTZ M. Nível de denudação atual do Complexo Alcalino de Poços de Caldas, MG-SP. In: CONGR. BRAS. GEOL., 35. Anais..., v. 6, p. 2633-2648, 1988.

MOTOKI, A., VARGAS, T. The Poços de Caldas Alkaline Complexo Rock Body, Minas Gerais - São Paulo, Brazil: A shallow mushroom-like phonolitic stoping body with kilometric megaxenoliths. Abstract Volume of 31st International Geological Congress, CD, 2000.

MOTOKI, A., VARGAS, T., HIRATA, D., ORIHASHI, Y., HALLER, M., ADRIANO, L., MOTTA, C.E. Estrutura subvulcânica do platô basáltico do Paraná comparado com a mesma dos vulcões monogênicos da Patagônia Argentina. Bol. Res. $8^{\circ}$ Simpósio de Geologia do Sudeste, 67, 2003b.

MOTOKI, A., ORIHASHI, Y., NARANJO, J.A., HIRATA, D., SKVARCA, P., ANMA R. Geologic reconnaissance of Lautaro Volcano, Chilean Patagonia. Revista 
Geológica de Chile, v. 33, n. 1, p. 177188, 2006.

MOTOKI, A., VARGAS, T., SILVEIRA, M. Perfil vulcano-estratigráfico de rochas basálticas da escarpa entre Caxias do Sul Nova Petrópolis, RS. Bol. Res. 51 ${ }^{a}$ Reunião Anual da SBPC, em CD, 1999.

NARANJO, J.A., SPEAKS, R.S.J., STASIUK, M.V., MORENO, H., ABLAY, G.J. Morphological, structural and textural variations in the 1988-1990 andesite lava of Lonquimay Volcano, Chile (38 $\mathrm{S}$ ). Geological Magazine, v. 129, p. 657-678, 1992.

ORIHASHI, Y., MOTOKI, A., HALLER, M. Petrogenesis of relatively large-volume basalts on extra-back arc province: Somuncura Plateau, northern Patagonia. Earth Monthly, v. 27, n.6, p. 438-447, 2005. (Em japonês).

ORIHASHI, Y., NARANJO, J.A., MOTOKI, A., SUMINO, H., HIRATA, D., ANMA, R., NAGAO, K. The Quaternary volcanic activities of Hudson and Lautaro volcanoes, Chilean Patagonia: new constraints from K-Ar ages. Revista Geológica de Chile, Special Issue, v. 31, n. 2, p. 207-224, 2004.

PEATE, D.W., HAWKESWORTH, C.J. MANTOVANI, M.S., SHUKOWSKY, W. Mantle plumes and flood basalt stratigraphy in the Paraná, South America. Geology, v. 18, p. 1223-1226,. 1990.

PEATE, D.W., HAWKESWORTH, C.J., MANTOVANI, M.S.M. Chemical stratigraphy of the Paraná lavas (South America): classification of magma types and their spatial distribution. Bull. Volcanol. v. 55, p. 119-139, 1992.
PHILLIPS, W.J. The dynamic emplacement of cone sheets. Tectonophysics, v. 24, p. 69-84, 1974.

RAMOS, V.A. Geología de la región del lago Cardiel, provincia de Santa Cruz. Revista de la Asociación Geológica Argentina, v. 37, p. 23-49, 1982.

REMESAL, M.B., MÉNDEZ, M.J., GAGLIADO, M.L. Petrología de la secuencia volcánica cenozoica en el área del arroyo Ranquil Huao: Meseta de Somún Curá. Patagonia Extraandina. Revista de la Asociación Geológica Argentina, v. 57, n. 3, p. 260-270, 2002.

ROSENBUSH, H. Mikroscopische Physiographie der Massigen Gesteine. Stuttgart. 4 edições: 1877, 1887, 1897, 1907.

SCHILLING, M., CONCEIÇÃO, R.V., MALLMANN, G., KOESTER, E., KAWASHITA, K., HERVÉ, F., MORATA, D., MOTOKI, A. Spinel-facies mantle xenoliths from Cerro Redondo, Argentine Patagonia: Petrographic, geochemical, and isotopic evidence of interaction between xenoliths and host basalt. Lithos, v. 82, n. 3-4, p. 485-502, 2005.

SEGEMAR. Mapa geológico de la Provincia de Rio Negro, 1:750.000. Secretaría de Minería de la República Argentina, Dirección Nacional del Servicio Geológico, 1994.

SILVEIRA, L.S., DUTRA, T., VALENTE, S.C., RAGATKY, D.C. Modelos eruptivos preliminares para o Complexo Vulcânico de Nova Iguaçu, RJ. In: SIMPÓSIO DE VULCANISMO E AMBIENTES ASSOCIADOS, 3. Anais..., p.333-337, 2005.
STEWART, K., TURNER, S., KELLEY, S., HAWKESWORTH, C., KIRSTEIN, L., MANTOVANI, M. 3-D, Ar-Ar geochronology in the Paraná continental flood basalt province. Earth and Planetary Science Letters, v. 143, p. 95-109, 1996.

STRECKEISEN, A.L. IUGS Subcommission on the Systematics of Igneous Rocks. Classification and nomenclature of volcanic rocks, lamprophyres, carbonatites and melilite rocks. Recommendations and Suggestions. Neues Jahrbuch für Mineralogie, v. 141, p. 114, 1978.

STRECKEISEN, A.L. Plutonic rocks classification and nomenclature recommended by the IUGS Subcommission on the Systematics of Igneous Rocks. Geotimes, v. 18, n. 10, p. 26-30, 1973.

ULBRICH, H.H.G.J. A petrografia, a estrutura e quimismo de nefelina sienitos do Maciço Alcalino de Poços de Caldas, MG-SP. São Paulo: Instituto de Geociências da Universidade de São Paulo, 1984. (Inédito) (Tese de Livre Docência).

ZIMBRES, E., MOTOKI, A. E., KAWASHITA, K. História de soerguimento regional da Faixa Ribeira com base em datações K-Ar. Boletim de Resumos de $36^{\circ}$ Congresso Brasileiro de Geologia. p. 315, 1990.

ZIRKEL, F. Die mikroskopisch Beschaffenheit der Mineralien unt Gesteine. Leipzig: 1837. 502p.

\section{Artigo recebido em 07/08/2005 e} aprovado em 14/03/2006.

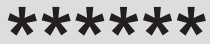

\section{REM - Revista Escola de Minas 70 anos divulgando CIÊNCIA.}

\author{
$* * * * * *$
}

www.rem.com.br

$* * * * * *$ 